Gut, 1979, 20, 255-258

\title{
Hepatocellular carcinoma in primary biliary cirrhosis: report of four cases
}

\author{
N. KRASNER, P. J. JOHNSON, B. PORTMANN, G. WATKINSON, \\ R. N. M. MACSWEEN, AND ROGER WILLIAMS
}

From the Liver Unit, King's College Hospital and Medical School, London, and the University Departments of Gastroenterology and Pathology, Western Infirmary, Glasgow

SUMMARY Of 98 patients dying with primary biliary cirrhosis only four developed hepatocellular carcinoma. It is suggested that the development of hepatocellular carcinoma is uncommon in this type of chronic liver disease because of its known female preponderance, and the fact that cirrhosis develops late in the course of the illness.

\begin{abstract}
Although hepatocellular carcinoma is a wellrecognised complication of many types of cirrhosis (MacSween and Scott, 1974; Gall, 1960), it has not previously been described in primary biliary cirrhosis. One report from America mentions 10 instances of this tumour arising in 'biliary cirrhosis', but no details are given (Purtilo and Gottlieb, 1973) and in three large series, comprising 98 patients with primary biliary cirrhosis(Ahrens et al., 1950;Sherlock, 1959; Hoff bauer, 1960), no instances of hepatocellular carcinoma were recorded. This report describes four patients with hepatocellular carcinoma arising in primary biliary cirrhosis seen at the Western Infirmary, Glasgow, and the Liver Unit, King's College Hospital, London, during the past 10 years. The possible factors responsible for the development of malignant change in this condition are analysed.
\end{abstract}

\section{Patients}

CASE 1

A 56 year old woman presented to King's College Hospital in 1957 with ankle swelling and, on examination, was found to have hepatomegaly. Investigations showed a serum bilirubin of $48 \mu \mathrm{mol} / \mathrm{l}$, alkaline phosphatase $216 \mathrm{IU} / \mathrm{l}$, and a raised $\gamma$ globulin $(58 \mathrm{~g} / \mathrm{l})$. An oral cholecystogram suggested the presence of granular material in the gall bladder. This was confirmed at laparotomy during which the liver was noted to be hobnail in appearance. Review of histological sections taken at that time showed changes characteristic of primary biliary cirrhosis. Although the architecture appeared to be cirrhotic, there was still evidence of damage to the few sur-

Received for publication 1 September 1978 viving bile ducts with dense lymphocytic infiltrates within some of the portal areas (Fig. 1). Two small epithelioid cell granulomata were also seen on this needle biopsy section.

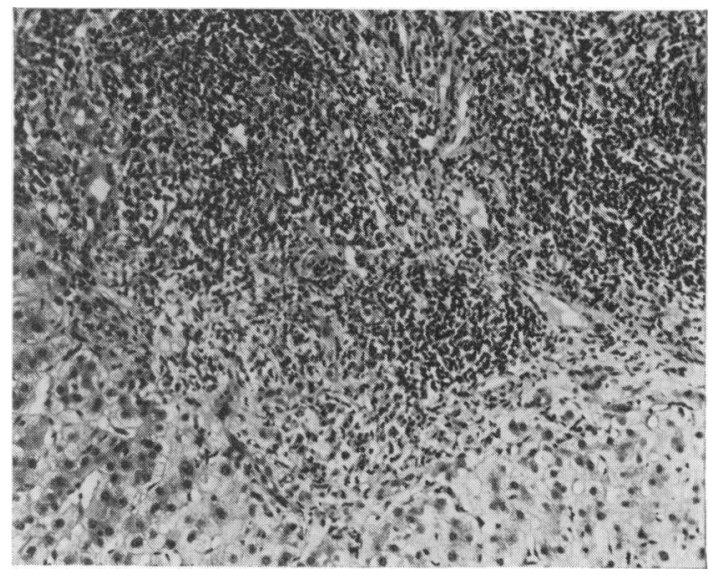

Fig. 1 Case 1. Liver needle biopsy specimen showing greatly enlarged portal area with dense predominantly lymphocytic infiltrate and a damaged interlobular duct on the left. $H$ and $E(\times 144$, original magnification $)$.

Liver function tests remained abnormal and in 1959 she first experienced pruritus, which was to persist until her death in 1967. During the intervening years she developed hepatic pre-coma on several occasions, which responded to correction of electrolyte imbalance and protein restriction. In 1966 antimitochondrial antibodies were found to be positive (titre 1/512). Death occurred after the sudden development of right-sided abdominal pain. Necropsy revealed massive bleeding into the perito- 
neal cavity from a large necrotic tumour in the right lobe of the liver. Histological appearances were those of a well-differentiated hepatocellular carcinoma with multi-nucleated giant tumour cells and evidence of bile secretion (Fig. 2).

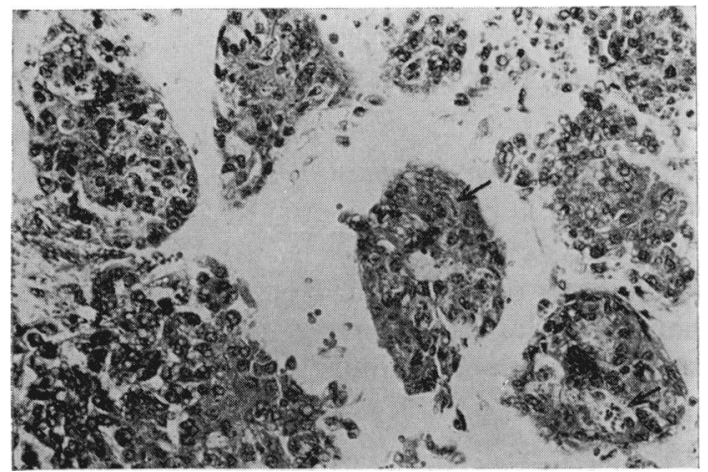

Fig. 2 Case 1. Needle specimen taken shortly after death. Dissociated elements of hepatocellular carcinoma showing multinucleated giant tumour cell transformation and bile pigment and plug deposition (indicated by arrows). $H$ and $E(\times 360$, original magnification).

\section{CASE 2}

A 51 year old woman presented to Stobhill Hospital, Glasgow, in 1967 with pruritus, at which time no abnormal physical findings were recorded. However, in 1968 she was found to have hepatosplenomegaly with numerous spider naevi. Investigation showed alkaline phosphatase $916 \mathrm{IU} / \mathrm{l}$, BSP $16 \%$ at 45 minutes, bilirubin $28 \mu \mathrm{mol} / \mathrm{l}$, and antimitochondrial antibodies positive at a titre of $1 / 512$.

Liver biopsy showed features typical of primary biliary cirrhosis with dense lymphocytic aggregates scattered among fibrous septa which were mostly devoid of interlobular bile ducts, while a bile duct lesion with granulomatous reaction was seen at one extremity of the specimen (Fig. 3).

The patient remained reasonably well until October 1971 when she became jaundiced (bilirubin $136 \mu \mathrm{mol} / \mathrm{l}$, alkaline phosphatase $690 \mathrm{IU} / \mathrm{l}$ ) with pale stools, and began to complain of abdominal pain. Barium swallow did not show oesophageal varices and a cholecystogram was normal. She became progressively more jaundiced and in February 1972 a liver scan revealed a filling defect in the right lobe. Liver biopsy showed a poorly differentiated carcinoma with trabecular pattern highly suggestive of hepatocellular carcinoma. The patient was given a course of chemotherapy but died at home four months later.
CASE 3

A 64 year old woman was admitted in May 1968 to Kilmarnock Infirmary after two haematemeses. On examination she had hepatosplenomegaly with signs of ascites. Biochemical investigations showed bilirubin $36 \mu \mathrm{mol} / 1$, alkaline phosphatase $210 \mathrm{IU} / 1$, globulin $35 \mathrm{~g} / \mathrm{l}$, and aspartate transaminase $60 \mathrm{IU} / 1$. A barium swallow demonstrated oesophageal varices. After two further haematemeses a splenorenal shunt was carried out, at which time the liver was described as showing a macronodular cirrhosis. She remained icteric but otherwise well until April 1972 when she suffered an episode of hepatic failure which settled rapidly with standard therapy. At this time antimitochondrial antibodies were found in the serum (titre 1/128). Two weeks later the patient had a further haematemesis and died the same day.

Necropsy revealed heavily blood-stained ascites and a macronodular cirrhosis in which there were several tumour nodules, the largest of which was

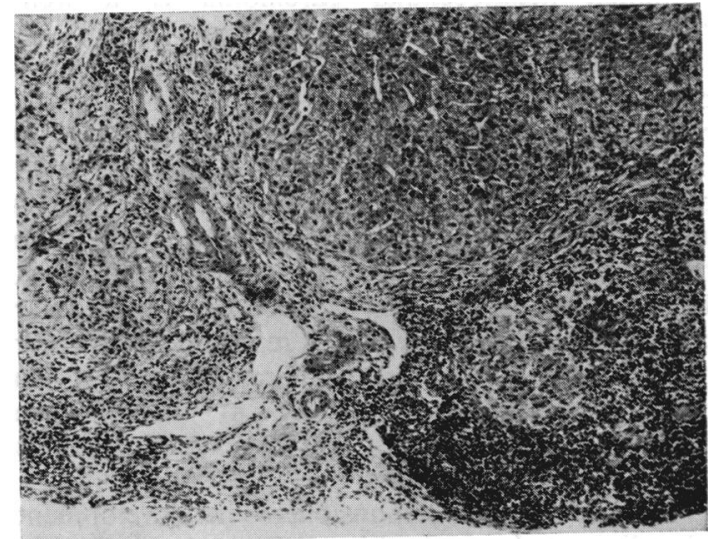

Fig. 3 Case 2. Needle biopsy. Primary biliary cirrhosis. Persistence of bile duct lesion and granulomatous reaction (bottom right) at late cirrhotic stage. Masson's trichrome $(\times 100$, original magnification).

$6 \mathrm{~cm}$ in diameter. Histologically, the tumour was a moderately well-differentiated hepatocellular carcinoma, exhibiting a trabecular pattern with areas of pseudoglandular formation (Fig. 4a). The nontumoral liver showed a macronodular cirrhosis. There was paucity of small bile duct elements among the fibrous septa where lymphocytic aggregates occurred, sometimes closely related to intact intermediate-sized bile ducts (Fig. 4b). At the periphery of some parenchymal nodules there was marked ductular proliferation and both Mallory bodies and orcein positive granules were present in liver cell cytoplasm; as has been described in long- 

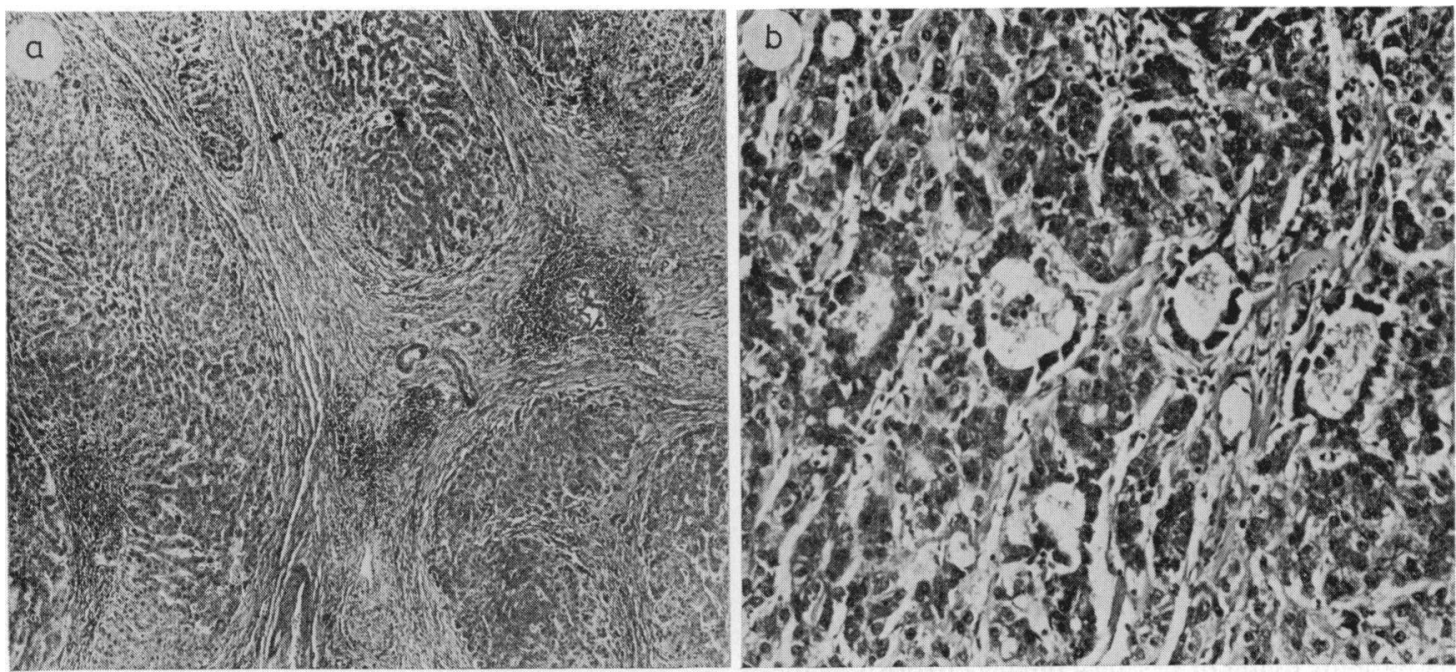

Fig. 4 Case 3. Block taken at necropsy. (a) Cirrhosis with fibrous septa mostly devoid of large interlobular ducts and containing lymphoid aggregates. $H$ and $E(\times 39$, original magnification). (b) Hepatocellular carcinoma with pseudo-glandular formation. Masson's trichrome ( $\times 124$, original magnification).

standing cholestatic liver diseases, particularly late primary biliary cirrhosis (Gerber et al., 1973; Salaspuro and Sipponen, 1976). These histological features were highly suggestive, if not diagnostic, of end-stage primary biliary cirrhosis.

\section{CASE 4}

A 56 year old man was admitted to the West Middlesex Hospital in July 1973 after several episodes of melaena. A barium meal suggested oesophageal varices and these were confirmed at endoscopy when gastric erosions were also noted. The patient had hepatomegaly and subsequent investigations at King's College Hospital showed an alkaline phosphatase level of $282 \mathrm{IU} / \mathrm{l}$, bilirubin 22 $\mu \mathrm{mol} / \mathrm{l}$, and positive antimitochondrial antibodies (titre 1/40). Liver biopsy showed a definite cirrhosis with lymphocytic collections often occurring within the fibrous septa where one would have expected to see interlobular bile ducts (Fig. 5). A mesentericocaval jump graft was successfully undertaken and the patient remained well until September 1975 when he began to complain of fatigue. Liver size was noted to be increasing. Repeat liver biopsy showed progression of the disease towards a picture of rather inactive cirrhosis with sparse bile ducts and the presence of both orcein positive granules and hyaline inclusions within liver cells near the interphase between parenchyma and fibrous septa. In October 1976 a mass was palpated in the liver at routine follow-up and biopsy revealed a welldifferentiated hepatocellular carcinoma. The patient died $2 \frac{1}{2}$ months later after a sudden bout of ab-

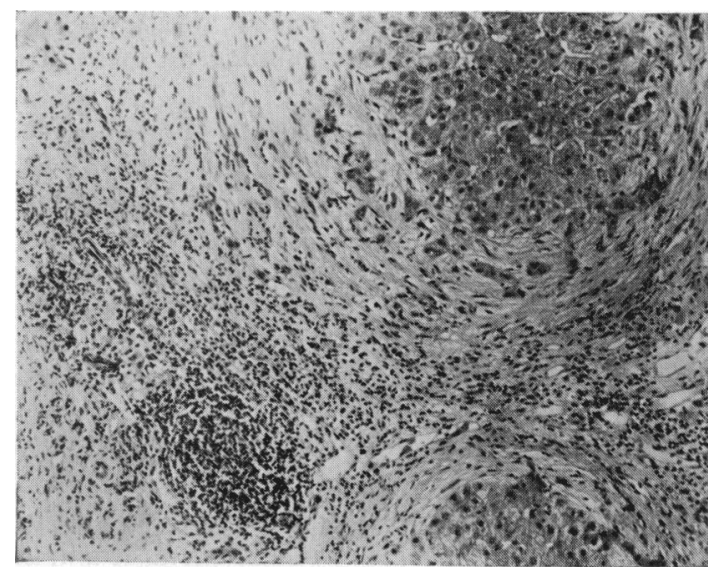

Fig. 5 Case 4. Needle biopsy, 1973. Zone of loose connective tissue at the margin of the fibrous septa which contain lymphocytic collection, while bile ducts of interlobular size are absent. $H$ and $E(\times 144$, original magnification).

dominal pain, paracentesis revealing heavily bloodstained fluid.

\section{Discussion}

There can be little doubt about the diagnosis of primary biliary cirrhosis in these four patients. Antimitochondrial antibodies were present in the serum of each patient and the histological features were diagnostic, or highly suggestive, of such a diagnosis. Similarly, the subsequent development of hepato- 
cellular carcinoma in each of the patients was confirmed by histological examination, and in cases 1 and 4 raised alpha-fetoprotein levels were also detected in the serum. Surprisingly, the terminal event in three patients was a massive bleeding from the tumour into the peritoneal cavity. Although this is a frequent complication in patients with hepatoma in Africa and the Far East (Ong and Taw, 1972), it is rare in Great Britain.

Although certain types of cirrhosis, such as haemochromatosis, would appear to be more likely to undergo malignant change than others (MacSween and Scott, 1974), tumour development also occurs frequently in alcoholic and cryptogenic cirrhosis, figures ranging from $12 \%$ (at Glasgow Royal Infirmary, a general hospital) (MacSween and Scott, 1974) to $25 \%$ (at King's College Hospital, a referral unit) (Krasner et al., 1976). An analysis of 98 patients dying of primary biliary cirrhosis at these two units over the last 10 years revelaed only four with a hepatoma. At least partly responsible for this low frequency is the marked preponderance of females in the present series (93 out of 98), as the occurrence of hepatocellular carcinoma in other types of cirrhosis is much commoner in males than in females.

Cirrhotic patients dying with hepatocellular carcinoma, both in our series and in those of other workers, are on average 10 years older than those who died from other causes (Krasner et al., 1976). This would suggest that the duration of cirrhosis is another important factor. Estimation of the duration of cirrhosis is often difficult, as the date when cirrhosis was first present is rarely known. However, overall in alcoholic cirrhosis it has been estimated that the mean minimum duration of cirrhosis needed for the development of hepatocellular carcinoma is eight years (Purtilo and Gottlieb, 1973). Cirrhosis is a late development in primary biliary cirrhosis and the mean survival from the onset of symptoms in one series was reported to be only 5.5 years (Sherlock, 1959). The four patients described here had had cirrhosis, as evidenced by surface appearances at operation or microscopically, for at least 10 , five, four and three years respectively, although, in general, once cirrhosis has developed, prolonged survival in this condition is unusual.

We are grateful to Dr J. B. Barr (consultant physician at Kilmarnock Infirmary) and Dr N. Cunningham (consultant pathologist at Ballochmyle Hospital) for permission to publish details of, and for provision of post-mortem material from, case 3, and to Dr N. Mackay (consultant physician at Victoria Infirmary) for permission to publish details of case 2 . The Cancer Research Campaign provided financial assistance and P. J. Johnson was supported by the Saltwell Research Fellowship from the Royal College of Physicians.

\section{References}

Ahrens, E. H., Jr., Payne, M. A., Kunkel, H. G., Eisenmenger, W. J., and Blondheim, S. H. (1950). Primary biliary cirrhosis. Medicine (Baltimore), 29, 299-364.

Gall, E. A. (1960). Primary and metastic carcinoma of the liver. Archives of Pathology, 70, 226-232.

Gerber, M. A., Orr, W., Denk, H., Schaffner, F., and Popper, H. (1973). Hepatocellular hyalin in cholestasis and cirrhosis: its diagnostic significance. Gastroenterology, 64, 89-98.

Hoffbauer, F. W. (1960). Primary biliary cirrhosis: Observations on the natural course of the disease in 35 women. American Journal of Digestive Diseases, 5, 348-383.

Krasner, N., Johnson, P. J., Bomford, A., Eddleston, A. L. W. F., and Williams, R. (1976). Hepatoma in chronic liver disease (Abstract). Gut, 17, 390.

MacSween, R. N. M., and Scott, A. R. (1974). Hepatic cirrhosis: a clinico-pathological review of 520 cases. Journal of Clinical Pathology, 26, 936-942.

Ong, G. B., and Taw, J. L. (1972). Spontaneous rupture of hepatocellular carcinoma. British Medical Journal, 4, 146149.

Purtilo, D. T., and Gottlieb, L. S. (1973). Cirrhosis and hepatoma occurring at Boston City Hospital (1917-1968). Cancer, 32, 458-462.

Salaspuro, M., and Sipponen, P. (1976). Demonstration of an intracellular copper-binding protein by orcein staining in long-standing cholestatic liver diseases. Gut, 17, 787-790.

Sherlock, S. (1959). Primary biliary cirrhosis (chronic intrahepatic obstructive jaundice). Gastroenterology, 37, 574-586. 